time in view of the desirability of making the British Isles less dependent on imports of wheat for its 'daily bread' (Cork : Forum Press. 2s.). He advocates the increased growing of rye, which is hardier than wheat and can be grown on poorer soils, and points out also that oaten and barley flour may without any dietetic disadvantage be used to eke out supplies of wheat. Growers of potatoes should be encouraged to set aside a portion of the crop for the production of potato flour, which is able to furnish us with our carbohydrate needs. It is interesting to note that flour was so scarce in England in 1800 that the Brown Bread Act was passed forbidding the use of pure white wheaten bread, and at this time flour was generally a mixture of equal parts of wheaten and rye flour. Wholemeal bread, of course, in contrast to white bread, contains comparatively large amounts of vitamins and minerals, although this is not the whole of the story.

\section{Origin of Cultivated Water-Melons}

Accordrng to Dr. Orland E. White of the University of Virginia, Africa, not America, is the native land of the water-melon. Speaking before the meeting of the Virginia Academy of Science, he told of recent researches at the Blandy Experimental Farm, which throw new light on the ancestry of this plant. Water-melons were not known at either the Epicurean feasts of ancient Greece or the Lucullan banquets of Rome. Not until the great age of exploration in the sixteenth century do they appear in the world picture. Dr. White is of the opinion that the Portuguese, pushing southward along the coast of Africa, became acquainted with the ancestors of modern water-melons growing wild in South Africa. They soon transferred them to their colony of Brazil, where the Indians promptly adopted them and added them to their own array of crops. Thus the myth of an American origin of water-melons came into being.

Dr. White has obtained seeds of several strains of these small wild South African melons, which have little enough resemblance to the monsters of the modern melon patch. He also has under cultivation stocks of a bitter variety of melon, known as the colocynth, familiar to the ancient Egyptians and other Mediterranean peoples, but used by them only as medicine. He has made many crossings between them and modern cultivated water-melons, some of which may eventually prove commercially valuable.

\section{Phenology of 1940}

With commendable promptness, the fiftieth Phenological Report of the Royal Meteorological Society, covering 1940, has just been issued despite war-time difficulties making it impossible for the executive committee to meet since the last report. With the exception of a small amount of introductory text, the report consists of a series of tables and diagrams, as has been its increasing trend in recent years. It has the observations of 288 phenological observers in the British Isles, compared with 385 in 1939. The publication of full moteorological details is still restricted, but it includes the events of the historic cold spell early in 1940, probably the coldest January for a hundred years and the sunniest for fifty years. The marked lateness of plants and insects caused by the cold opening of the year gave place to considerable earliness which mainly persisted from the end of April, with a succession of warm, mild spells, and the beauty of spring and early summer was enhanced by the simultaneous occurrence of normally early species which had been retarded and the normally later species which were brought forward.

This recovery also applied to crops, although some autumn-sown cereals failed to survive the winter. The droughty conditions in May, June, and, after a cool showery July, again in August and early September, had an interesting effect upon the grass; in the north-west the assessed condition remained between 77 and 78 per cent throughout August, whereas in the south-east it deteriorated from about 77 per cent to about 56 per cent, during which period the rainfall was about 30 per cent of the average in the north-west but only 3 per cent in the south-east. Indigenous insects are unlikely to have been affected so much as indigenous birds, which, however, had a favourable nesting season after so hard a winter. Migrants arrived at dates not far from average in the south but somewhat later in the north, while the only large-scale insect immigration was that of the large white butterfly (Pieris brassicae). The comparative earliness of the north-west district is shown in the plant and insect diagrams, in advance of the south-east up to May.

\section{Design of Wire Networks Carrying Radio Programmes}

In the Bell Laboratories Record of April there is an instructive paper by A. E. Bachelet explaining some of the difficulties encountered when designing wire networks over which radio programmes are transmitted. These in America often form extensive systems with broadcast stations or studios in most of the larger systems interconnected by high-quality crreuits employing amplifiers. The transmission over these circuits differs from ordinary telephone transmission in that it is unidirectional, and one-way amplifiers are employed. Since a studio may either transmit or receive programmes, it is necessary to provide means for changing the direction of transmission over the network. In the past this has been done either by using separate facilities which transmit in opposite directions, or by interchanging the input and the output of the amplifiers by the use of switches manually operated.

To provide quicker reversals, a remotely controlled reversing circuit has been developed which permits the reversal of the circuits to be controlled from the studio originating the programme. Reversals are effected by relays, controlled by direct current transmitted over the two conductors of the programme circuit, and returned through the earth. Any studio may assume control and set up the network so as to transmit the programme from it to the other points on the network. As long as this studio 
retains control, no other studio can alter the conditions. The reversing equipment is required at every amplifier point, which may be a simple amplifier station along the line, or a main junction or terminal connecting to a broadcast studio.

\section{Swiss Electrotechnical Industry during War-time}

IN the February issue of Swiss Technics, a journal published by the Swiss Office for the Development of Trade (Zurich and Lausanne), which co-operates with the Swiss Association of Machinery Manufacturers, Zurich, there is an instructive account of a visit made to the Secheron Works at Geneva. These works have always been strictly limited to the construction of heavy electrical machinery and material. A few years ago, when the electrification of the chief Swiss railroads, to which the Secheron Works greatly contributed, drew to a close, new lines of manufacture were tuken up. Among these was the building of electric welding apparatus and the manufacture of the necessary electrodes. The Secheron alternatingcurrent arc-welding apparatus has now almost everywhere replaced direct-current revolving units. For the welding of complicated parts 'exotherme' electrodes are almost universally employed; cut-out or stamped parts can be simply welded together by the melting of the electrode into the space left between them, thus forming a solid block as homogeneous as a foundry casting.

Enormous alternators for the hydro-electric power station of Verbois are now being constructed at the works. These machines resemble two-storied towers, $9 \cdot 2$ metres high and each weighing 300 tons. All parts are electrically welded and every welding has been carefully inspected by radiograph. At normal speed the peripheral speed of the polar wheel will be equal to $155 \mathrm{~km}$. per hour; at $300 \mathrm{rev}$. per min. this speed attains $350 \mathrm{~km}$. per hour. A 3,000-h.p. motor is being built for Norway and twelve transformers of $1,000,2,000$ and $3,200 \mathrm{kva}$. are being built for Ireland.

\section{Electro-formed Reflectors}

THE construction recently of 62 -in. searchlight reflectors at the Bart Laboratories, New Jersey, shows, according to the Electrical Review of April 11, that satisfactory progress is being made in modern electro-forming methods. An electro-formed nickelsurfaced mould is first of all made and a coat of nickel $0.003-0.005 \mathrm{in}$. thick is applied to the outer passivated nickel face. Then follows a coating of copper, to which a pre-formed bronze ring is applied, and the assembly is given a heavy deposit of copper. These firmly bonded layers are stripped from the mould in the form of a bi-metal reflector with copper on the convex face and nickel on the inner polished face. To prevent the introduction of copper into the rhodium bath, a protective mask is fitted on the copper side. The reflector is now ready to receive its rhodium-plating, and in this instance a 'flash' of rhodium 30 millionths of an inch thick appears satisfactory.

The advantage of this method appears to be in the use of rhodium on a nickel base. It has a high hardness (about 600 Brinell), is tightly adherent to its underlying layer, and also has a high degree of reflectivity and resistance to tarnish. The coatings of rhodium used are exceptionally thin; but as nickel is passive when plated with rhodium, adequate protection is provided. It is stated that full protection is lacking with underlayers of copper and its alloys, the relation of which to rhodium in electro-chemical action is such that disfigurement by corrosion may result.

\section{Japan Institute for the Science of Labour}

THE annual report of the Director of the Japan Institute for the Science of Labour for 1939, recently received, in reviewing the present activities of the Institute, emphasizes its objectives in assisting the development of the national industrial capacity, including the training of workers, as well as the improvement of working conditions, and the stimulation of leadership. Reference is made to the investigation. of industrial hazards as well as of the problems of agricultural workers, including their maintenance. A somewhat naive claim is made for the uniqueness of the Institute, as well as a reference to its part in the establishment of a 'New Order' in the Orient. The report also includes the director's address on the "Function and Guiding Spirit of the Institute", given at its first staff conference, in which the character of the Institute as a purely scientific research body covering the daily life of the industrial and agricultural worker is emphasized, and also the importance of its contribution to national productivity and culture. Stress is laid upon the team spirit in the research work of the Institute and its service of social and national needs. Details of the various research sections and laboratories of the Institute are given, as well as of projects already under investigation.

\section{Thin Glass for Microscope Cover-Slips}

THE year 1940 marked the centenary of the manu. facture in Great Britain of specially thin glass for microscope cover-slips. Prior to this date, it was customary for microscopists to use thin talc or mica for covering specimens to be examined under the microscope. This manufacture was started by Messrs. Chance Brothers and Co., Ltd., at Smethwick, in 1840 as nearly as is known, and has been carried on continuously by the same firm up to the present day. The War has called for a considerable increase in supplies of such glass, both in Great Britain and abroad. There was no essential change in this type of glass until about 1928 , when a research was carried out on the development of microscope cover-slips. It was found that the old type of glass, which was essentially like window glass, would not withstand tropical conditions without becoming clouded. Therefore, new methods of manufacturing a glass which would withstand sterilizing and exposure to tropical atmospheres without any deterioration were introduced. The thickness of cover-slip glass is still classified under the headings: Extra thin $(0.075-$ $0.100 \mathrm{~mm}$.$) , No. 1(0 \cdot 100-0 \cdot 167 \mathrm{~mm}$.$) , No. 2(0 \cdot 167$ - 